\title{
Editorial
}

This year the journal enters its thirtieth year of publication and our editor reaches his seventieth birthday, and completes 10 years of dedicated assiduous work in the editorial chair.

When the International Medical Society of Paraplegia was founded in 1961 a journal became a natural development. The journal Paraplegia was launched in 1963 by $\mathrm{Sir}$ Ludwig Guttmann, editor of the editorial board, and we shared his wish for its prosperity. At its outset, the journal was published quarterly. Continuing strides in the field of spinal injuries necessitated the expansion of the journal and from 1980 there were 6 issues per year, 9 issues from 1990 and from the beginning of this year the journal will be published monthly.

Credit is due to our editor for his foresight and unrelenting determination in achieving this expansion, allowing the journal to become a magnet for all relevant publications. Our editor should be congratulated on his ability to attract to the editorial board eminent specialists in spinal injuries and the allied branches of medicine, surgery and the paramedical professions who are able to uphold the standards of the publication.

Since its onset the journal has emphasised the importance of the specialty and has contributed to its worldwide standing and, recently, in the United Kingdom, to the Royal Colleges' accreditation of specialty training in spinal injuries. The unique nature of a spinal injury and the resultant multisystem effects demand special coordination to manage the medical, surgical, psychological and physical aspects. The journal has increasingly provided a platform for doctors, scientists and paramedical professionals to communicate their experiences, views and findings, enabling and enhancing individual and institutional developments and advances. The journal provides a vehicle for sharing professional experiences of the value of spinal injuries centres, encouraging the continuing establishment of new centres worldwide. Descriptions of the many facets of spinal injuries and the working of established and evolving centres has aided many professionals in setting up their own services.

From its onset, the journal has published most of the pioneering work of Guttmann, Munro, Frankel and the first generation of paraplegists. The work of these early specialists was responsible for the understanding of the pathophysiology of spinal injuries, enabling clinicians not only to reverse the trend of survival of our patients but also to devise ways of improving their quality of life.

The last decade, in particular, has witnessed a number of new developments in the management of patients with spinal injuries. Our editor and his board were quick to react and the reader will be aware that our journal was pre-eminent in publishing the following developments: computerised tomography and magnetic resonance imaging in the management of the spinal injury; recent advances in the management of excess spasticity with intrathecal Baclofen; improvement in the management of fertility with vibroejaculation and electroejaculation; improvement of the quality of ambulation and the reduction of its energy cost with the hip guidance orthosis and parawalker; the potential benefits of functional electrical stimulation to respiration, locomotion, improvement of hand functions and control of micturition; the advances in the management of the neuropathic bladder and the value of urodynamics; the value of spinal cord monitoring; advances of surgical techniques on the spinal axis and the paralysed hands; and recently advances in research on spinal cord regeneration. We also mention that our journal offers a unique venue for the expression of differing views of management and controversial topics, thus enabling the reader to reach a balanced overall view.

Mr Phillip Harris took over the editorialship of Paraplegia following the sudden death of Sir Ludwig Guttmann in 1980, having served previously as assistant editor from the inception of the journal. His vast 
experience and his innovations and contributions to the field of neurosurgery, spinal injuries and to our journal are innumerable. He is a Fellow of the Royal Society of Edinburgh. He is also a member of many learned societies, Scottish, British and international. $\mathrm{He}$ is a founder member and chairman or past chairman of many learned societies, including the International Medical Society of Paraplegia and the Scottish Association of Neurological Sciences, a founder member and immediate past president of the British Cervical Spine Society, and Director of Spinal Injury Studies of the World Federation of Neurosurgical Societies.

$\mathrm{He}$ has been instrumental in the instigation and the development of many spinal injuries centres in different parts of the world. A visiting professor and guest lecturer to many institutions, he recently had the privilege to deliver the Donald Munro

\section{Message from the publisher}

This is a special issue of the journal in more than one way. It marks the thirtieth anniversary of Paraplegia's publication as a major medical title, it is also the tenth year of $\mathrm{Mr}$ Phillip Harris as editor, and of least importance to most readers but of great significance to me marks, literally, the birth day of Macmillan as the publisher of the journal.

As a new boy it is inappropriate for me to attempt to recall the events of the past 30 years since Professor Sir Ludwig Guttmann founded both the International Medical Society of Paraplegia and this journal others more competent than I will most certainly do so. I am sure however that most of the major innovations and attendant discussion on all aspects of spinal injury have appeared in the pages of this journal over the years and will continue so to do.
Lecture in the United States of America. $\mathrm{Mr}$ Phillip Harris has recently been elected president of the Rotary Club of Edinburgh, an honour bestowed on few.

Our editor is reaching his seventieth birthday and his tenth anniversary as the editor of our 30 year old journal. We commence this year with a new publisher and a much improved format, confident that our journal will continue to be the main reference for clinicians in the field, for authors in and related to the field and for future generations of clinicians.

We extend our best wishes to the readers of Paraplegia, and to the editorial board. To our editor we also express our special thanks from two loyal colleagues of the journal.

\section{W S El Masry MB B Ch FRCSE \\ Assistant Editor \\ J T Hughes MD FRCP FRCPath \\ Assistant Editor}

When a journal has been as successful as Paraplegia it becomes something of an institution in its own right. One learns not to trifle with an institution lightly! The changes you will see in this issue of Paraplegia, a revised cover and, we hope, more pleasing typography, are less significant than the change to a monthly publication schedule. This change in the frequency of publication should allow more material to be published expeditiously in future.

Macmillan are delighted to be associated with the Society in the publication of this the thirtieth anniversary issue and look forward with them to developing the journal in its next decade.

Harry Holt 